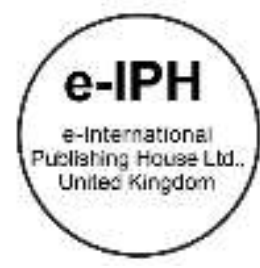

\title{
A Cataract Surgery Barrier Model in Eastern Zone of Peninsular Malaysia
}

\author{
Abdul Mutalib 1, Nurulain Mat Zin ${ }^{2}$, Ahmad Shahir ${ }^{3}$, Asma Hassan 1 \\ ${ }^{1}$ Faculty of Medicine, Universiti Sultan Zainal Abidin, 20400 Kuala Terengganu, Terengganu, Malaysia \\ 2 Department of Ophthalmology, Hospital Kuala Krai, 18000, Kuala Krai, Kelantan, Malaysia \\ ${ }^{3}$ Department of Occupational Therapy, Faculty of Health Sciences, Universiti Teknologi MARA, Puncak Alam, 42300, Selangor, \\ Malaysia
}

abdulmutalib@unisza.edu.my, safain84@gmail.com, shahirmutalib@gmail.com, asmahassan@unisza.edu.my Tel: +60139275801

\begin{abstract}
Cataract is a serious public health problem as it is the most common cause of blindness in Malaysia and globally. Timely cataract surgery is required to prevent visual loss. This model illustrates the barriers in accessing cataract surgery services in the eastern zone of Peninsular Malaysia. Factors identified are personal issues, followed by issues at the primary care and specialist care level. This model is designed to elucidate the effect of delayed presentation, detection, and referral procedure for the provision eye care and cataract surgery to prevent blindness required to maintain the best quality of life and wellbeing.
\end{abstract}

Keywords: Cataract blindness; Cataract surgery; Barriers; Interpretative phenomenological analysis

eISSN: 2398-4287 @ 2018. The Authors. Published for AMER ABRA cE-Bs by e-International Publishing House, Ltd., UK. This is an open access article under the CC BYNC-ND license (http://creativecommons.org/licenses/by-nc-nd/4.0/). Peer-review under responsibility of AMER (Association of Malaysian Environment-Behaviour Researchers), ABRA (Association of Behavioural Researchers on Asians) and cE-Bs (Centre for Environment-Behaviour Studies), Faculty of Architecture, Planning \& Surveying, Universiti Teknologi MARA, Malaysia.

https://doi.org/10.21834/e-bpj.v3i9.1500

\subsection{Introduction}

Cataract is a common condition characterised by the development of a progressive opacity in the crystalline lens of the eye causing deterioration of vision leading to blindness. The World Health Organization (WHO) defines severe cataract blindness as patients with visual acuity worse than $3 / 60$ in the better eye caused by cataract $(\mathrm{WHO}, 2007)$. Although easily curable by surgery, it remains a serious public health problem as the single most important cause of global blindness commonly affects the older people (Bourne, Flaxman, Braithwaite, et al., 2017). The second Malaysian National Eye Survey (NES2) conducted in 2014, similarly revealed it as the leading cause of visual impairment and blindness among older people aged 50 and above in the whole country (Salowi, 2014). This situation indicates the presence of barriers that hinder patients with cataract in Malaysia to undertake earlier cataract surgery before becoming severely blind. They are problematic situations acted as the factor of hindrance for patients to undergo the cataract surgery required for visual recovery ((Irfan, Irfan \& Spiegel, 2012).

Currently, there is no universally accepted health care barrier model or a comprehensive framework which cover all health conditions from the various perspectives on the concept of health care barriers (Irfan, et al., 2012; Mclntyre, Thiede \& Birch, 2009). Generally, authors have described it in five different dimensions in terms of the availability, accessibility, affordability, adequacy, and acceptability of health care provision (Obrist, Iteba, Lengeler, et al. 2007). Other models, such as the Health Belief Model, attempted to characterise it within the overall perspectives of health care seeking behaviour, such as the Theory of Reasoned Action, the Theory of Planned Behaviour, and the Andersen's Model of Health Services Utilisation (Andersen, 2008). The Andersen's behavioural model emphasises the influence of needs, predisposing, and enabling factors on health care services provided for the population (Andersen, 2008). The utilisation of health care services was also found to be determined by social structure, demographics, attitudes, and the peoples' beliefs of diseases (Irfan, et al., 2012). However, all these models are lacking the focus to specifically define and explain the barriers towards accessing eye care and cataract surgery.

eISSN: 2398-4287 @ 2018. The Authors. Published for AMER ABRA cE-Bs by e-International Publishing House, Ltd., UK. This is an open access article under the CC BYNC-ND license (http://creativecommons.org/licenses/by-nc-nd/4.0/). Peer-review under responsibility of AMER (Association of Malaysian Environment-Behaviour Researchers), ABRA (Association of Behavioural Researchers on Asians) and cE-Bs (Centre for Environment-Behaviour Studies), Faculty of Architecture, Planning \& Surveying, Universiti Teknologi MARA, Malaysia.

https://doi.org/10.21834/e-bpj.v3i9.1500 
There are barriers to accessing the eye care and cataract surgery in Malaysia as the national prevalence of severe cataract blindness is relatively high in the country despite the widespread availability of ophthalmology services in all major Ministry of Health (MOH) hospitals (Salowi, 2014). Thus, we need to identify and address these barriers in order to further improve the uptake of cataract surgery. This study aims to identify the multi-level factors which have led to the delay in cataract surgery uptake, and to suggest a comprehensive solution towards earlier detection, effective counseling, and prompt referral to specialists for the cataract surgery required to prevent blindness. The objective is to explore and characterise all possible barriers by investigating how patients with severe cataract blindness made sense of their lived experiences endured during the state of progressive deterioration of vision until severe blindness.

\subsection{Methodology}

In this study, we selected participants from the Eastern zone of Peninsular Malaysia which includes the states of Kelantan, Terengganu and Pahang. This study was approved by the Human Research Ethics Committee of the Universiti Sultan Zainal Abidin, Kuala Terengganu (Ref no.: UniSZA.C/1/UHREC/628-1(64) dated 2 May 2016). We identified participants with severe blindness in both eyes due to cataract, confirmed by qualified optometrists directly involved in the patients' management. The criteria for inclusion into the study for the in-depth, face-to-face interview includes those who have cataract with the best corrected visual acuity in the better eye worse than 3/60, fluent in Malay, and aged above 50 years old. Identified patients with speech or language difficulty, and have associated significant ocular or systemic co-morbidity are excluded. The summary of the total of eleven study participants is listed in Table I.

Table 1: Characteristic of all the study participants identified by their abbreviated names

\begin{tabular}{|c|c|c|c|c|c|c|c|c|}
\hline \multirow[t]{2}{*}{ No. } & \multirow[t]{2}{*}{ Abbr. } & \multirow[t]{2}{*}{ Gender } & \multirow[t]{2}{*}{ Age } & \multicolumn{2}{|c|}{ Visual acuity } & \multirow{2}{*}{$\begin{array}{l}\text { Marital } \\
\text { status }\end{array}$} & \multirow[t]{2}{*}{ Location } & \multirow[t]{2}{*}{ Socio-economic status } \\
\hline & & & & Right & Left & & & \\
\hline 1. & Y & $\mathrm{F}$ & 59 & CF & CF & Married & $\begin{array}{l}\text { Besut, } \\
\text { Terengganu }\end{array}$ & Good. Own house, car and land \\
\hline 2. & 1 & M & 54 & CF & $\mathrm{CF}$ & Married & $\begin{array}{l}\text { Besut, } \\
\text { Terengganu }\end{array}$ & $\begin{array}{l}\text { Very poor. Stays in house rendered by } \\
\text { government }\end{array}$ \\
\hline 3. & $\mathrm{~T}$ & $\mathrm{~F}$ & 72 & HM & PL & Widow & $\begin{array}{l}\text { Kok Lanas, } \\
\text { Kelantan }\end{array}$ & $\begin{array}{l}\text { Good. Lives with adult child who was a } \\
\text { teacher }\end{array}$ \\
\hline 4. & $\mathrm{R}$ & $\mathrm{F}$ & 51 & CF & $2 / 60$ & Divorcee & $\begin{array}{l}\text { Tumpat, } \\
\text { Kelantan }\end{array}$ & Moderate. Lives with her daughter \\
\hline 5. & $\mathrm{~F}$ & $\mathrm{~F}$ & 72 & $\mathrm{CF}$ & CF & Widow & $\begin{array}{l}\text { Temangan, } \\
\text { Kelantan }\end{array}$ & $\begin{array}{l}\text { Good. Living in her own house with son to } \\
\text { look after her }\end{array}$ \\
\hline 6. & A & $\mathrm{F}$ & 51 & $\mathrm{CF}$ & $\mathrm{CF}$ & Married & $\begin{array}{l}\text { Kuala Krai, } \\
\text { Kelantan }\end{array}$ & $\begin{array}{l}\text { Poor. Lives in surrogate house. Husband has } \\
\text { no fixed income }\end{array}$ \\
\hline 7. & J & $\mathrm{F}$ & 72 & HM & $2 / 60$ & Widow & $\begin{array}{l}\text { Kuala Krai, } \\
\text { Kelantan }\end{array}$ & $\begin{array}{l}\text { Moderate. Lives on social welfare stipends } \\
\text { with physically handicapped son }\end{array}$ \\
\hline 8. & $\mathrm{HZ}$ & M & 81 & $1 / 60$ & $2 / 60$ & Married & $\begin{array}{l}\text { Bukit lbam, } \\
\text { Pahang }\end{array}$ & Good. Has two houses and fruit orchard \\
\hline 9. & TC & $\mathrm{F}$ & 70 & $1 / 60$ & HM & Widow & $\begin{array}{l}\text { Rompin, } \\
\text { Pahang }\end{array}$ & $\begin{array}{l}\text { Moderate. Stays with her daughter's family. } \\
\text { Own a house in Jerantut Pahang. }\end{array}$ \\
\hline 10. & KT & $\mathrm{F}$ & 73 & PL & $\mathrm{HM}$ & Widow & $\begin{array}{l}\text { Kemaman, } \\
\text { Terengganu }\end{array}$ & $\begin{array}{l}\text { Good. Stays with her daughter's family. Own } \\
\text { a house }\end{array}$ \\
\hline 11. & HS & $\mathrm{F}$ & 63 & PL & HM & Widow & $\begin{array}{l}\text { Kemaman, } \\
\text { Terengganu }\end{array}$ & $\begin{array}{l}\text { Good. Alternately stays with her mother and } \\
\text { daughter }\end{array}$ \\
\hline
\end{tabular}

(Legend: Abbr.: Abbreviation; F: Female; M: Male; CF: Counting fingers; HM; Hand movement; PL: Perception of light)

A standardised interview protocol as recommended by Plummer-D'Amato (2008) facilitated the step-by-step interview procedures with an in-depth approach at the participants' own homes. In order to maintain the originality of the perspectives of our participants, the verbatim transcription, analysis and identification of themes were done in their native language or dialect. Only one investigator (NMZ) was involved in conducting all the interviews, guided by a standardised interview format enhanced by a pilot study on three participants not included in the actual study. Every participant gave their written consent for the interview, with or without the presence of immediate family members. All participants granted their special permission to use a digital audio recorder to record the interview sessions. They were encouraged to describe their lived experiences in detail from the early stage of their progressive loss of vision until blindness. Using the local Malay dialect in the interview has facilitated excellent rapport and good responses from the participants. The trust generated accurate accounts of their encountered life situations throughout the 60 to 90 minutes of face-to-face interactions. It has allowed us to explore the various aspects of their lived experiences from the time they aware of the blurring of vision until the stage of blindness. They mainly highlight their needs for better sight by any well-recalled and dramatic events. Our question begins with 'why did you unwilling to accept cataract surgery' has brought patients to the exact point in searching for the negative side of the event. They described their experiences in chronology on what, where, when and why, in order to make sense of their phenomenological life events related to the progressive loss of their sight. Exchanges of information in their native dialect also allowed more natural understanding and agreement of the researchers during analysis of the transcripts.

Their non-verbal communication such as their sitting posture, eye movement, eye fixation, eye-hand coordination, and facial expression such as smiling, provided significant information in evaluating the detailed perspectives their verbal responses. Their home environment, infrastructure, personal involvement, bonding, and activities with their family were exploited to relate the scenario to what 
was said by the participants. Houses furnished with settee chairs, LCD television, and branded items are being considered to have good socio-economic status whereas small, unpainted, and not fully furnished houses are considered as poor.

The audio recording was typed verbatim, and the transcript was analysed by two independent researchers using the six stages of interpretative phenomenological analysis (IPA) approach designed by Smith, Flowers and Larkin (2009). The IPA approach offers much deeper understanding of their experience during visual deterioration where participants are actively engaged in making sense of the significant and unexpected things which happen to them (Smith, 2016). It involves data familiarisation and immersion, followed by the validation process of its theoretical comments and finally verified by matching the situational analysis of the participant. The last participant was determined as the end-point for this study when the analysis did not provide any additional new theme indicating the achievement of data saturation. Connections between the initial themes of the coded quotes were listed and further scrutinised to develop deeper understanding before contacting the next participant. Strict adherence to the similar steps in the analysis process ensured every transcript had similar chances of identifying identical or new themes. The NVivo software version 8.0 facilitated the coding of all the quotes representing the initial themes from all the transcripts obtained. The identified themes were merged, classified and finally constructed into main themes and subthemes, organised in the manner to achieve the research objectives. Two co-researchers acted as independent researchers verified every identified theme and resolved any conflict of opinions at every step of the analysis. The original quotes and themes in the Malay language were maintained throughout the whole process of verbatim transcription, analysis and identification of themes.

\subsection{Findings}

We distinguish three main themes identified as barriers corresponding to the level of health care namely at the personal, primary care, and specialist care level. The barriers at the personal level are issues pertaining to their perceived need for sight, activities of daily living (ADL), apprehension, physical status, family support and financial adversity. Barriers at primary care level are nondisclosure of their visual problems due to delayed awareness of their visual status, belated needs for better sight, social stigma, and problems on patientprovider-related issues such as miscommunication and delayed referral, which occur even in the convenience and regular access to the primary care providers. At the final level of care by the specialists, we identified problems pertaining to accessibility, bureaucracy, waiting time and cost related to the cataract surgery. The themes and subthemes identified are related to the participants' perception as their barriers to undertake cataract surgery, in line with the progression of visual loss in the order consistent with the standard clinical practice and eye care service provision. The selected themes and their related quotes, translated into English for the preparation of the manuscript with the agreement of all the authors, are tabulated in Table 2 below.

\subsection{Discussion}

Our current research findings identified factors at the personal level by themes or issues perceived as the initial barriers towards cataract surgery. This level reflects the attitude of patients with cataract in accepting and adapting their visual loss as a natural phenomenon of ageing, resulting in negative thoughts about cataract surgery. They were apprehensive about their physical status and capabilities before, during and after the contemplated surgery as they are committed to maintain their ADL for the needs of their family members (Mutalib, et al., 2016). They are also deeply concern about the effects on the livelihood and care of their family members with regard to the time, effort and cost incurred for surgery. However, their continuous engagement in ADL and occupational activities were proven to have facilitated their sense of purpose and quality of life (Ibrahim \& Dahlan, 2015). Their decisions are affected by the amount of moral and physical support they could give and get from their family members, deemed as one of the essential components for the quality of life and wellbeing among Malaysian (Aisyah et al., 2016). These are reasons for their initial refusal to disclose their visual problem to family members and primary care providers.

The current health care system in Malaysia requires all patients to go through the primary care providers for the detection and diagnosis of cataract and for the referral to the ophthalmologist for the appropriate care. Although they regularly visit primary care providers for common ailments, diabetes mellitus, hypertension and asthma, our patients tend to ignore their visual problem. They tend to avoid the social stigma of needing the special attention. It is similar to an earlier study which noted most of their elderly patients often seek treatment for common disorders such as diabetes (92\%), hypertension (90\%), joint complains (54\%) and dental problems (47\%), but with considerable contrast to visual problems (20\%) and memory impairment (13\%) (Mahesh et al., 2013). Some of our participants revealed that miscommunication is still a major barrier due to the ignorance of doctors at the primary care level regarding cataract and its surgical treatment and failed to alleviate patients' refusal attitude to disclose their poor vision leading to delayed in diagnosis and the referral needed for specialist care.

At the final level of care by the specialist, four main issues identified as barriers are accessibility, administrative bureaucracy, waiting time and cost of surgery. Many countries, such as India, have studied barriers to cataract surgery extensively for many years and have noted changes in the trend. Earlier studies have identified factors such as need not felt, poverty, and poor transportation as the major barriers, whereas barriers in the rural population were related to cost, accessibility and lack of awareness (Vaidyanathan, et al., 1999; Kovai, et al., 2007). However, recent study is more consistent with our findings which showed issues associated with attitude, referral processes and eye care provision (Dhaliwal \& Gupta, 2007; Irfan, et al., 2012). 
Table 2: Themes identified as barriers to cataract surgery with examples of their related quotes

\begin{tabular}{|c|c|c|}
\hline $\begin{array}{l}\text { Main } \\
\text { theme }\end{array}$ & Subtheme & Quotes \\
\hline \multirow[t]{6}{*}{$\begin{array}{l}\text { Personal } \\
\text { level }\end{array}$} & $\begin{array}{l}\text { Perceived need for } \\
\text { sight }\end{array}$ & $\begin{array}{l}\text { I don't have any problem although my vision is blurry. Only one eye was poor at that time but I am still strong. } \\
\text { I can still work as a gardener. (Madam KT: PL, HM, Terengganu) }\end{array}$ \\
\hline & $\begin{array}{l}\text { Activities of daily } \\
\text { living (ADL) }\end{array}$ & $\begin{array}{l}\text { My son had a motor vehicle mishap at the age of 23, he is now } 40 \text { years old. Since then, he could only sit all } \\
\text { day long and crawl to the toilet. I have to switch on the TV for him. I have been looking after him as there is } \\
\text { nobody else can do that. I used to feed him, and scrub him when he takes his bath. Otherwise he will just sits } \\
\text { still and keeps both his hand to his body. (Madam J: HM, 2/60, Kelantan) }\end{array}$ \\
\hline & Apprehension & $\begin{array}{l}\text { Some of my relatives said there is no need to do the eye surgery. My vision can become worse and I can die } \\
\text { during the eye surgery. (Madam F: CF both eyes, Kelantan) }\end{array}$ \\
\hline & Poor physical status & $\begin{array}{l}\text { Both my legs hurt very much and cannot move at times. I have gone for a medical check-up but the doctor } \\
\text { doesn't know the problem. What's the point of going for surgery if my condition is still in the current state? I } \\
\text { can't walk and I can't see, then I will be in pain with both illness. (Mr HZ: } 1 / 60,2 / 60 \text {, Pahang) }\end{array}$ \\
\hline & Poor family support & $\begin{array}{l}\text { I was thinking whether to have the surgery or not? It is because I might cause much inconvenience to others } \\
\text { as I have no one to take care of me after the surgery. (Madam A: CF both eyes, Kelantan) }\end{array}$ \\
\hline & Financial adversity & $\begin{array}{l}\text { My husband only works for } 15 \text { days in the last Ramadhan. He is jobless since that day (sad and wiping her } \\
\text { eyes). He has not been able to get any job for the last few months. How are we going to eat, what more to } \\
\text { undergo the eye surgery? (Madam A: CF both eyes, Kelantan) }\end{array}$ \\
\hline \multirow[t]{5}{*}{$\begin{array}{l}\text { Primary } \\
\text { care level }\end{array}$} & $\begin{array}{l}\text { Delayed awareness } \\
\text { of their visual status }\end{array}$ & $\begin{array}{l}\text { I don't know about my eyes. I have been going regularly to the nearby health center for my medication. I had } \\
\text { no intention to ask the doctor about my eyes even if I can barely see. Can they check my eyes too? (Madam } \\
\text { H: PL, HM, Terengganu) }\end{array}$ \\
\hline & $\begin{array}{l}\text { Belated needs for } \\
\text { better sight }\end{array}$ & $\begin{array}{l}\text { I am still able to cook rice using the rice cooker. I can ask my grandchild to come and tell me either it is done } \\
\text { or not. (Madam TC: } 1 / 60, \mathrm{HM} \text {, Pahang) }\end{array}$ \\
\hline & Social stigma & $\begin{array}{l}\text { I don't know why I don't want to tell anyone (smiling). I just want to keep my eye problem a secret but they } \\
\text { found out about it themselves. I don't want them to worry about me. (Madam T: HM, PL, Kelantan) }\end{array}$ \\
\hline & Miscommunication & $\begin{array}{l}\text { I have told the doctor about my eyes while I had my blood pressure check-up. But the doctor ignored my } \\
\text { complaint. Even during the next visit, my daughter told the doctor about my eyes, but similarly the doctor } \\
\text { ignored it also. Finally, when my vision is much worse, only then the doctor noted it and referred me to the } \\
\text { specialist. My right eye could barely see and I was depending on my left eye. (Madam J: HM, 2/60, Kelantan) }\end{array}$ \\
\hline & Delayed referral & $\begin{array}{l}\text { I told the doctor about my eye problem in } 2015 \text { (i.e. } 2 \text { years ago). The doctor also has checked my eyes. } \\
\text { However, the nurse went for a course and there was no one else replacing her until lately. (Madam HS: PL, } \\
\text { HM, Terengganu) }\end{array}$ \\
\hline \multirow[t]{4}{*}{$\begin{array}{l}\text { Specialist } \\
\text { care level }\end{array}$} & Accessibility & $\begin{array}{l}\text { I was staying in Maran, it is quite near to the district hospital, but from Maran to Temerloh Hospital it is too far. } \\
\text { (Madam R: CF, } 2 / 60 \text {, Kelantan) }\end{array}$ \\
\hline & $\begin{array}{l}\text { Administrative } \\
\text { bureaucracy }\end{array}$ & $\begin{array}{l}\text { I used to go to the specialist clinic to check my eye once a year due to my diabetes. I have not gone to the } \\
\text { clinic since I lost my appointment card in the flood. My eye sight was still pretty good at that time. Now it is } \\
\text { bad. (Madam F: CF both eyes, Kelantan) }\end{array}$ \\
\hline & $\begin{array}{l}\text { Waiting time for } \\
\text { surgery }\end{array}$ & $\begin{array}{l}\text { I went to the eye clinic in June. I thought I can immediately have the operation done, but they told me that the } \\
\text { vacancy is only available in September. It is already October, the hospital still has not call me yet. (Madam } \\
\text { KT: PL, HM, Terengganu) }\end{array}$ \\
\hline & $\begin{array}{l}\text { Cost related to } \\
\text { cataract surgery }\end{array}$ & $\begin{array}{l}\text { I can't get help from anyone. I did ask the Social Welfare Department, but I was rejected as I was too young. } \\
\text { I only have five hundred ringgit that I have saved. (Madam R: CF, 2/60, Kelantan) }\end{array}$ \\
\hline
\end{tabular}

(Legend: CF: Counting fingers; HM; Hand movement; PL: Perception of light)

Promoting awareness among individuals, community and government and non-governmental sectors by taking advantage of their relationship and interdependence with their family and community members was advocated to be an effective and important approach to ensure early screening for cataract detection and surgical uptake (Nurulain, et al., 2018). Opportunistic screening for the visual status during every visit to any health facilities was also highly recommended as part of the routine check-up for all patients above 50 years old. This measure is worth trying as the NES2 revealed the national prevalence of low vision of $5.5 \%$, ranging from $4.6 \%$ to $9.4 \%$ in all zones in Malaysia (Chew, et al., 2018). Addressing the identified barriers at all level of care can further enhance a much earlier uptake of cataract surgery in our community as the most effective way to improve their vision, wellbeing and quality of life. 


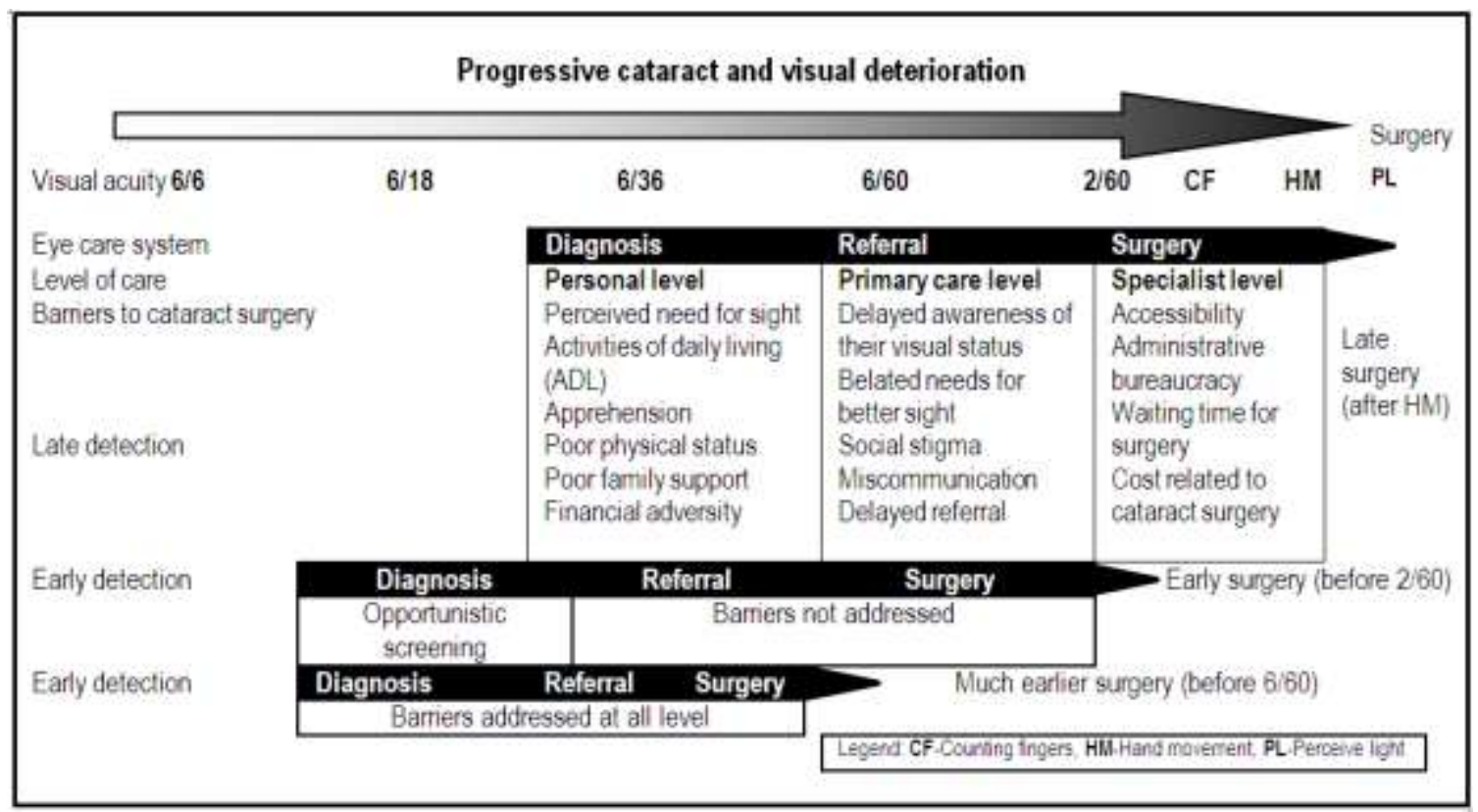

Fig. 1: Cataract surgery barrier model in the eastern zone of Peninsular Malaysia

Figure 1 illustrates the importance of addressing the barriers at all level of care to achieve earlier cataract surgery uptake. The arrow represents the progressive visual loss from 6/6 to perception of light $(\mathrm{PL})$ due to cataract. Barriers at the personal, primary care and specialist care levels explain the reasons for the delay in detection of cataract and the subsequent late uptake of cataract surgery. Addressing the barriers by opportunistic screening for early detection will result in earlier cataract surgery uptake. Additional improvement by addressing the barriers at all level will further intensify the effectiveness of ensuring a much earlier cataract surgery uptake. This concept was not addressed and described in any of the previous health care barrier models. We are optimistic that our proposed cataract surgery barrier model will be able to convince policy-makers involve in the eye care on the methods to improve the eye care delivery system. However, as in any qualitatively designed studies, the limitation of this study includes limited representation and might not be able to represent the whole population of the eastern zone of Peninsular Malaysia. The study was unintentionally more representative of the Malay in rural areas, and their perspectives might have limited extrapolation of the multiracial population of Malaysia. Therefore, further study is strongly advocated to address other specific population groups in Malaysia.

\subsection{Conclusion \& Recommendations}

Employing the IPA approach in this study has effectively recognised the barriers to cataract surgery among patients with severe cataract blindness in the eastern zone of Peninsular Malaysia. The comprehensive IPA approach successfully identified themes by understanding how the patients made sense of their lived experiences during the period of their progressive loss of vision concerning their needs, feeling, commitment and ADL with their family, community members, health care providers and finally the health care authorities. The factors are classified into three levels, starting at the patients' personal level followed by the primary care and finally the specialist care level. An in-depth interpretation of those who deny, delay or agree to undertake cataract surgery is essential in recognising the barrier at every level of health or eye care. This will allow us to address the problem in a more effective ways not well described in any previous health care barrier model. It is a major contribution in the quest to increase the efficiency of health and eye care system to promote prevention of blindness by earlier cataract surgery uptake in Malaysia.

\section{Acknowledgements}

This study was fully self-sponsored by all the contributing authors without any external grant. The authors would like to thank the assistance of all the optometrists for identifying the study participants. The advice on data collection and analysis by lecturers in the Faculty of Medicine and the Faculty of Social Sciences, UniSZA is much appreciated. Finally, we also wish to thank all the study participants and family members for their cooperation during the entire interaction in this study.

\section{References}

Aisyah, A.B., Mariana, M.O., Syahriah, B., \& Mansor, I. (2016). Investigating Rationales of Malaysia Quality of Life and Wellbeing Components and Indicators. Procedia - Social and Behavioural Sciences, 222, 132-42. 
Andersen, R.M. (2008). National health surveys and the behavioural model of health services use. Med Care, 46, 647.

Bourne, R.R.A., Flaxman, S.R., Braithwaite, T., Cicinelli, M.V., Das, A., Jonas, J.B., et al. (2017). Vision Loss Expert Group. Magnitude, temporal trends, and projections of the global prevalence of blindness and distance and near vision impairment: a systematic review and meta-analysis. Lancet Glob Health, 5(9), e888-97.

Chew FLM, Salowi MA, Mustari Z, Husni MA, Hussein E, Adnan TH, et al. (2018) Estimates of visual impairment and its causes from the National Eye Survey in Malaysia (NESII). PLOS ONE, 13(6), e0198799.

Dhaliwal, U., \& Gupta, S.K. (2007). Barriers to the uptake of cataract surgery in patients presenting to a hospital. Indian J Ophthalmol, 55(2), 133-6.

Ibrahim, S.A.S. \& Dahlan, A. (2015). Engagement in Occupational Activities and Purpose in Life amongst Older People in the Community and Institutions. Procedia Social and Behavioural Sciences, 202, 263-72.

Irfan, F.B., Irfan, B.B., \& Spiegel, D.A. (2012). Barriers to accessing surgical care in Pakistan: Healthcare barrier model and quantitative systematic review. J Surg Res, $176,84-94$.

Kovai, V., Krishnaiah, S., Shamanna, B.R., Thomas, R., Rao, G.N. (2007). Barriers to accessing eye care services among visually impaired populations in rural Andhra Pradesh, South India. Indian J Ophthalmol, 55(5), 365-71.

Mahesh, C., Suraj, K., Kishor, D., Sumit, U., Naresh, M., Dipesh, P. (2013). Morbidity pattern and treatment seeking behaviour of geriatric population in Jamnagar city. Journal of Research in Medical and Dental Science, 1(1), 12-16.

Mclntyre, D., Thiede, M., Birch, S. (2009). Access as a policy-relevant concept in low- and middle-income countries. Health Econ Policy Law, 4(2), 179.

Mutalib, A.S.A., Dahlan, A., Masuri, M.G., \& Danis, A. (2016) Interdependence among Malay older people who live in the community: An Interpretative Phenomenological Analysis. Procedia - Social and Behavioural Sciences, 234, 90-7.

Nurulain, M.Z., Shahir, A., Asma, H., \& Mutalib, A. (2018) Primary Care Barriers to Cataract Surgery in the Eastern Zone of Peninsular Malaysia: An Interpretative Phenomenological Analysis. Med J Malaysia, 73(2), 67-72.

Obrist, B., Iteba, N., Lengeler, C., et al. (2007). Access to health care in contexts of livelihood insecurity: A framework for analysis and action. PLoS Med, 4 , 1584.

Plummer-D’Amato. (2008). Focus Group Methodology Part 1: Consideration for design. International Journal of Therapy and Rehabilitation, $15(2), 69-73$.

Salowi, M.A. (2015). National Eye Survey Report 2014. Ophthalmology service: Ministry of Health Malaysia. Kuala Lumpur.

Smith, J.A. (2016). Interpretative phenomenological analysis: Getting at lived experience. The Journal of Positive Psychology, $12(3), 1-2$.

Smith, J.A., Flowers, P., \& Larkin, M. (2009). Interpretative Phenomenological Analysis: Theory, method and research. SAGE Publications Inc.

Vaidyanathan, K., Limburg, H., Foster, A., Pandey, R.M. (1999). Changing trends in barriers to cataract surgery in India. Bull World Health Organ, 77(2), 104-9.

World Health Organization. (2007). Vision 2020 - Global initiative for the elimination of avoidable blindness: action plan 2006-2011. Report of a WHO Working Group. Geneva. 